University of Nebraska - Lincoln

DigitalCommons@University of Nebraska - Lincoln

\title{
Evaluation of Stomoxys calcitrans (Diptera: Muscidae) Behavioral Response to Human and Related Odors in a Triple Cage Olfactometer with Insect Traps
}

\author{
Raul A. Alzogaray \\ USDA-ARS \\ David A. Carlson \\ USDA-ARS
}

Follow this and additional works at: https://digitalcommons.unl.edu/usdaarsfacpub

Part of the Agricultural Science Commons

Alzogaray, Raul A. and Carlson, David A., "Evaluation of Stomoxys calcitrans (Diptera: Muscidae) Behavioral Response to Human and Related Odors in a Triple Cage Olfactometer with Insect Traps" (2000). Publications from USDA-ARS / UNL Faculty. 980.

https://digitalcommons.unl.edu/usdaarsfacpub/980

This Article is brought to you for free and open access by the U.S. Department of Agriculture: Agricultural Research Service, Lincoln, Nebraska at DigitalCommons@University of Nebraska - Lincoln. It has been accepted for inclusion in Publications from USDA-ARS / UNL Faculty by an authorized administrator of DigitalCommons@University of Nebraska - Lincoln. 


\title{
Evaluation of Stomoxys calcitrans (Diptera: Muscidae) Behavioral Response to Human and Related Odors in a Triple Cage Olfactometer with Insect Traps
}

\author{
RAÚL A. ALZOGARAY ${ }^{1,2}$ AND DAVID A. CARLSON ${ }^{2}$
}

\begin{abstract}
J. Med. Entomol. 37(3): 308-315 (2000)
ABSTRACT A triple cage olfactometer provided with insect traps was used for evaluating behavioral responses of Stomoxys calcitrans (L.) females to human skin and breath, $\mathrm{CO}_{2}$, and L-lactic acid analogs. After demonstrating there were no significant differences caused by cage location or time of day, 3 sets of 3 olfactometer tests were performed in a day, every $2 \mathrm{~h}$ beginning at 0900 hours. When a human hand was used as attractant, the attraction (expressed as percentage of trapped flies) increased as a function of the time; an inverted $U$-shaped relationship between attractancy and air speed was observed; and variation in fly density in the range $25-75$ per cage did not affect the attraction response. When human breath was used as attractant the attraction increased linearly as a function of time and it was exhalation frequency dependent; when air flow was absent the highest response was observed; and 24- to 38-h-old flies were more attracted than younger and older. When $\mathrm{CO}_{2}$ was tested, activation and orientation and probing behavior were concentration dependent with flows ranging between 0.0001 and 0.038 liter $\mathrm{s}^{-1}$, but attraction was not. No attraction was observed with 10,100 , or $1,000 \mu \mathrm{g}$ of compounds related to L-lactic acid and several synthetic human odors and related compounds, although orientation was often observed.
\end{abstract}

KEY WORDS Stomoxys calcitrans, stable fly, host-location behavior, triple cage olfactometer, human odors

ThE STABLE FLY, Stomoxys calcitrans (L.), is a hematophagous insect whose economic impact as a pest of livestock is well established (Campbell et al. 1977, Campbell et al. 1987, Wieman et al. 1992). Both sexes of the stable fly bite mammals and suck blood. Bunching by livestock and the energy used to combat the effects of stable fly feeding activity have been indicated as causes of weight loss in animals (Wieman et al. 1992). These flies have also been shown to transmit a number of disease organisms (Foil and Hogsette 1994). S. calcitrans also feed on humans (Newson 1977), with particularly severe and prolonged difficulties occurring along the Gulf Coast near the Florida-Alabama border. Outbreaks also have been reported along Atlantic coast beaches and several inland locations.

Host odors are an important cue in host location by blood-sucking flies (Gibson and Torr 1999). S. calcitrans activation (an increasing of flight activity) and orientation responses to human odors in laboratory conditions were previously evaluated using wind tunnels without integral insect traps (Gatehouse and Lewis 1973; Warnes and Finlayson 1985a, 1985b). Gatehouse and Lewis (1973) quantified orientation by

\footnotetext{
${ }^{1}$ Centro de Investigaciones de Plagas e Insecticidas (CIPEIN/ CITEFA-CONICET-UNSAM), Zufriategui 4380, (1603) Villa Martelli, Prov. Buenos Aires, Argentina.

${ }^{2}$ Center for Medical, Agricultural and Veterinary Entomology, USDA-ARS, 1600/1700 S.W. 23rd Drive, Gainesville, FL 32604.
}

counting the number of flies landing on an artificial target. In this experimental design, repeated landings by individuals could not be excluded from the counts, so that the total number of landings does not necessarily represent a direct measure of the real number of landings. Furthermore, both treated and control targets were located inside the same experimental chamber, and some insects activated by the olfactory stimulus may have been induced to land on the control target in response to a visual stimulus. Warnes and Finlayson (1985b) quantified the orientation of stable flies by recording their distribution along a 2.5-m tunnel before and after stimulation by potential attractants. In this case, it was not possible to distinguish between a mere orientation and a more precise attraction to the stimulus source. It is important to distinguish these 2 behavioral responses because some stimuli can elicit only the former response.

The objective of the current work was to develop a methodology for evaluating the different steps of behavioral responses of $S$. calcitrans to olfactory stimuli (activation, orientation, precise attraction and probing) using a triple cage olfactometer with insect traps (Posey et al. 1998). We determined the responses to human skin and breath, $\mathrm{CO}_{2}$, known mosquito attractants including L-lactic acid related compounds (Carlson et al. 1973), and chemicals produced by humans as previously identified by others (Ellin et al. 1974, Krotoszynski et al. 1977, Cork and Park 1996). 


\section{Materials and Methods}

Biological Material. The stable flies used in this work were from a colony maintained at the Center for Medical, Agricultural, and Veterinary Entomology (CMAVE, USDA). The colony, founded $20 \mathrm{yr}$ ago, was maintained at $26^{\circ} \mathrm{C}$ and $70 \% \mathrm{RH}$, and the larval diet was according to Hogsette (1992). Adults were fed citrated cow's blood. Males responded less readily to candidate attractants in preliminary tests. For this reason, all experiments in this work were performed with 24- to 36-h-old females that were absolutely starved from emergence, unless otherwise stated.

Chemicals. The following compounds were purchased from Aldrich (Milwaukee, MI): glycolic acid, oxalic acid, DL-glyceric acid, DL-malic acid, succinic acid, adipic acid, pentane, 1-octen-3-ol, 4-hexen-1-ol, acetone, and 4-methyl-3-penten-2-one. Other compounds were DL-mandelic acid from Lancaster (Windham, NH), hexane from Burdick and Jackson (Muskegon, MI), and 1-octyn-3-ol from Bedoukian (Danbury, CT).

The Triple Cage Olfactometer. Our system was described in detail by Posey et al. (1998). It was constructed from clear acrylic $(8 \mathrm{~mm})$, and had 3 cages stacked vertically, supported on a single base. Each cage had paired sleeves and insect traps. An opening in the rear of each test cage, which is covered with $0.7-\mathrm{mm}$ mesh window screen in a frame, allows insects to acclimatize to the air being used in the tests. For measuring activation, the fly traps were reversed to block the trap port and keep all the insects in the test cage for the test period.

A plywood box $(62 \mathrm{~cm}$ long by $109 \mathrm{~cm}$ high by 67.5 $\mathrm{cm}$ wide) was placed outdoors, and fitted with a squirrel cage fan which provided an air flow, a heater with thermostat, a humidifier, and an air inlet ( 30 by $30 \mathrm{~cm}$ ) covered with a charcoal-loaded air filter. Filtered outdoor air was transported by the fan through $4 \mathrm{~cm}$ o.d. PVC tubing. Air temperature and humidity were controlled by the heater and the humidifier, respectively. Environmental conditions inside the olfactometer were monitored with a thermo-hygrometer, and air flow was measured with an anemometer. During testing, temperature and relative humidity were $24-28^{\circ} \mathrm{C}$ and $66-77 \%$, respectively. Air flow was $0.25-$ $0.30 \mathrm{~m} \mathrm{~s}^{-1}$, unless otherwise stated.

Direct physical contact with all olfactometer parts and surfaces during testing was avoided by wearing latex gloves to minimize contamination by skin oils.

Testing. Flies were sexed in the afternoon using a cold table adjusted to $4^{\circ} \mathrm{C}$. Separated females were recollected on the next day from stock cages using a hand-held aspirator and placed into the test cages $1 \mathrm{~h}$ before testing (25-55 individuals per cage, unless otherwise stated). When the ports in each test cage were closed, clean fly traps and sleeves were mounted in position. Among experiments, temperature varied between 24 and $28^{\circ} \mathrm{C}$, relative humidity was $65-75 \%$.

The response to human skin was evaluated using the right hand of one of the authors (R.A.A.) as attractant. The hand was washed once with water and soap $2 \mathrm{~h}$ before the 1st experiment. After introducing the hand into one of the sleeve assemblies, the iris diaphragm was closed tightly around the wrist. The adjacent sleeve assembly without an introduced hand was used as a control.

For evaluating the response to human breath, a plastic tube (30 cm long, $1.5 \mathrm{~cm}$ diameter) was introduced into one of the sleeve assemblies, and the iris diaphragm was closed around it, leaving one of its ends outside the olfactometer. One of the authors (R.A.A.) exhaled through the tube (10 exhalations per minute unless otherwise stated).

$\mathrm{CO}_{2}$ was introduced from a cylinder via a needle valve and flowmeter. L-lactic acid-related compounds were dissolved in acetone. One hundred microliters of solution were placed into white vial caps $(0.23 \mathrm{~cm}$ diameter) $15 \mathrm{~min}$ before experiments. After solvent evaporation, 10,100 , or $1,000 \mu \mathrm{g}$ of compound remained in the caps. The other compounds tested were liquids, and they were applied at different volumes using $20 \mathrm{~mm}$ glass tubes supported vertically $(225 \mu \mathrm{l}$, $3 \mathrm{~mm}$ diameter) or a small black vial cap ( $400 \mu \mathrm{l}, 9 \mathrm{~mm}$ diameter). Each compound was tested at 3 volumes: 1 or 3 glass tubes, or a black vial cap. For testing other pure compounds, the white caps or the containers were placed into one of the sleeve assemblies. White caps treated with acetone alone, or empty containers were used as controls, respectively. Activation and subjective observations of orientation were recorded, but only 1-2 replicates of each test were done every time that attraction was not obvious and was no higher than $3.3 \%$.

In each test, the number of flies were counted as they passed through the screen cone into the trap during a 6-min period (unless otherwise stated). At the end of each test, the number of flies in the control trap and in each cage was counted. For measuring activation (an increase in flight activity) and orientation (movement of the flies against the olfactometer air flow), the fly traps were reversed to block the trap port to keep all the insects in the test cage for the test period. Activation was expressed as percentage of flies remaining on the cage's rear screen after applying the attractant minus the number of flies on the screen before the attractant was offered. Orientation was expressed as percentage of flies staying in the front one-fifth of the total cage volume after the treatment was applied with respect to the number of flies in the same space before the beginning of the treatment. In activation and orientation experiments, 50 flies were placed into each cage. Air flow was $0.25-0.30 \mathrm{~m} \mathrm{~s}^{-1}$.

Probing was evaluated by placing 1 fly into an olfactometer trap. The exit of the trap was blocked with a cork. After acclimatization, the cage port was opened to allow air flow through the trap. Simultaneously, the $\mathrm{CO}_{2}$ flow was applied from a tube located $5 \mathrm{~cm}$ from the trap front. Probing behavior, extension of proboscis through the mesh screen with a stabbing action, was recorded.

Normally, 3 sets of 3 tests were performed every day, every $2 \mathrm{~h}$ beginning at 0900 hours. Within each set of tests, the order of cage selection was randomized. 
Table 1. Mean \pm SE percent attraction of $S$. calcitrans females to a human hand

\begin{tabular}{|c|c|c|c|c|}
\hline \multirow{2}{*}{ Cage } & \multicolumn{3}{|c|}{ Time, hours } & \multirow{2}{*}{$\begin{array}{c}\text { Mean/ } \\
\text { cage }\end{array}$} \\
\hline & 0900 & 1100 & 1300 & \\
\hline 1 & $0 \pm 1.9$ & $12.3 \pm 1.8$ & $14.8 \pm 2.2$ & $13.7 \pm 1$ \\
\hline 2 & $2 \pm 2.4$ & $19.3 \pm 2.3$ & $15.2 \pm$ & $16.2 \pm 1$ \\
\hline 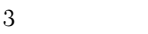 & $17.3 \pm 2.2$ & $13.3 \pm 2.2$ & $13.1 \pm 1.2$ & $14.5 \pm 1$ \\
\hline Mean/time & $15.2 \pm 1.2$ & $15.0 \pm 1.3$ & $14.4 \pm 1.2$ & \\
\hline
\end{tabular}

There were no significant differences caused by time $(P=0.32)$ nor cage position $(P=0.18)$. All values were significantly different than their respective controls $(P \leq 0.00002)$. Each value is the mean of 12 replicates $(n=25-55)$.

Each experiment was replicated 6 or 12 times (unless otherwise stated), and different flies were used in each replication

Statistical Analysis. After checking homogenicity of variance and normality of data, they were analyzed using analysis of variance. Log transformation was done when necessary. Means were separated using the Tukey honestly significant difference test. Linear regression and chi-square tests were also used (Sokal and Rohlf 1969). Each attraction mean value was compared with its respective control using the nonparametric Mann-Whitney Utest (Sokal and Rohlf 1969).

\section{Results}

Table 1 shows mean attraction at 3 times of day in the triple cage olfactometer. There were no significant differences because of cage position $(F=1.14, \mathrm{df}=98$, $P=0.32)$ or time of day $(F=1.59, \mathrm{df}=98, P=0.18)$. Mean attraction responses varied through time by $<5.1 \%$, and mean responses through cage position varied among cages by $<7 \%$. The range in mean responses for all combinations of cage positions and time of day was $12.3-19.3 \%$. Control values varied between 0 and $2.7 \pm 0.8 \%$. The differences between each mean response and its respective control were highly significant in all cases $(P \leq 0.00002)$.

Because temperature varied between 24 and $28^{\circ} \mathrm{C}$ during testing, replicates were grouped according to the temperature and were statistically analyzed (Table 2). There were no significant differences between values $(F=0.25$, $\mathrm{df}=91, P=0.86)$.

The mean attraction varied linearly as a function of the time at different air flows $\left(y=-2.5+2.9 x ; r^{2}=\right.$ 0.996 , at $0.10-0.15 \mathrm{~m} \mathrm{~s}^{-1} ; y=7.7+4.2 x ; r^{2}=0.901$, at

Table 2. Mean $\pm \mathrm{SE}$ percent attraction of $S$. calcitrans females to a human hand at different temperature ranges

\begin{tabular}{lc}
\hline Temp, ${ }^{\circ} \mathrm{C}$ & Attraction, \% \\
\hline $24-25$ & $15.2 \pm 1.5$ \\
$25-26$ & $15.5 \pm 1.4$ \\
$26-27$ & $14.3 \pm 1.4$ \\
$27-28$ & $17.7 \pm 1.7$ \\
\hline
\end{tabular}

No significant differences between values were observed $(P=$ $0.86)$. All values were significantly different than their respective controls $(P \leq 0.00002)$. Each value is the mean of at least 7 replicates $(n=25-55)$.

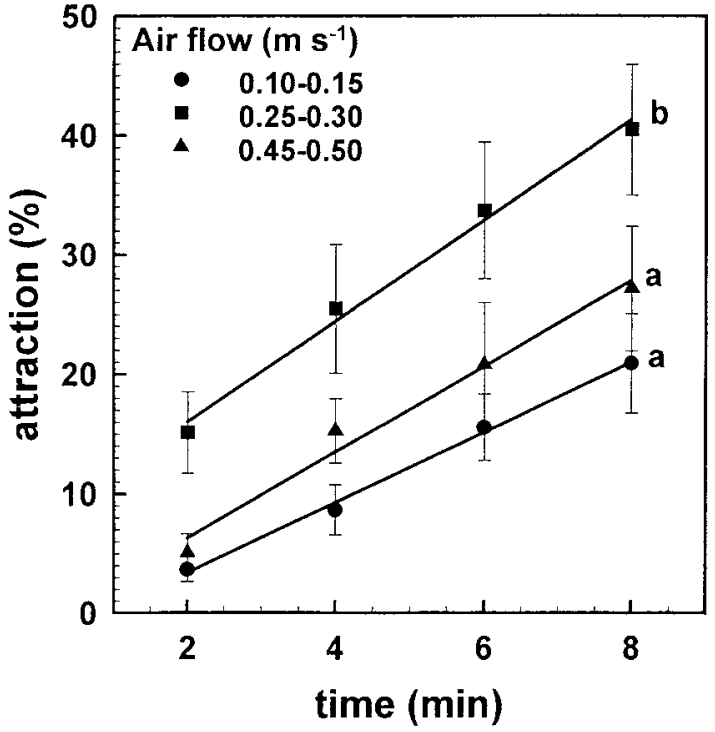

Fig. 1. Time-attraction relationship of S. calcitrans females to a human hand at 3 air flows. Different letters indicate significant differences caused by air flow $(P<0.05)$. Each value is the mean of 6 replicates $(n=25-55)$. Vertical lines are standard error.

$0.25-0.30 \mathrm{~m} \mathrm{~s}^{-1}$; and $y=-0.9+3.6 x ; r^{2}=0.980$, at $0.45-0.50 \mathrm{~m} \mathrm{~s}^{-1}$ ) (Fig. 1). Attraction at $0.25-0.30 \mathrm{~m} \mathrm{~s}^{-1}$ was significantly higher than at other air flows $(P<$ $0.05)$. There was no significant difference between mean responses at $0.10-0.15$ and $0.45-0.50 \mathrm{~m} \mathrm{~s}^{-1}(P=$ $0.50)$.

The mean attraction was not significantly affected by variation in fly number in the range $25-75$ flies per cage $(F=0.22$, $\mathrm{df}=15, P=0.81)$ (Fig. 2$)$.

Figure 3 shows that mean attraction varied linearly as a function of the time when human breath was used as attractant $\left(y=-1.6+1.2 x, r^{2}=0.999\right.$, at 5 exhalations per minute; and $y=0.9+1.9 x, r^{2}=0.957$, at 10 exhalations per minute). At 10 exhalations per minute, significantly higher attraction was observed $(F=7.1, \mathrm{df}=7, P=0.03)$.

The air flow had a significant effect on attraction $(F=18.7, \mathrm{df}=2, P=0.0002)$ (Fig. 4$)$. The highest attraction was observed when air flow was absent.

The age of flies had a significant effect on attraction $(F=3.1, \mathrm{df}=5, P=0.03)$ (Fig. 5). Flies that were 24-26 and $36-38 \mathrm{~h}$ old were significantly more attracted than other ages $(P<0.05)$.

Results in Table 3 indicate that $\mathrm{CO}_{2}$ failed to attract flies into traps, as the mean attraction was not significantly different from control at any flow rate $(P \geq$ $0.09)$. Human breath, used as positive control in this experiment, trapped a significant number of flies with respect to control $(P=0.02)$.

Figure 6 shows that significant activation was recorded when $0.001(F=9.2, \mathrm{df}=48, P<0.000001)$ and $0.01(F=18.0, \mathrm{df}=48, P<0.000001) \mathrm{ml} \mathrm{s}^{-1}$ of $\mathrm{CO}_{2}$ 


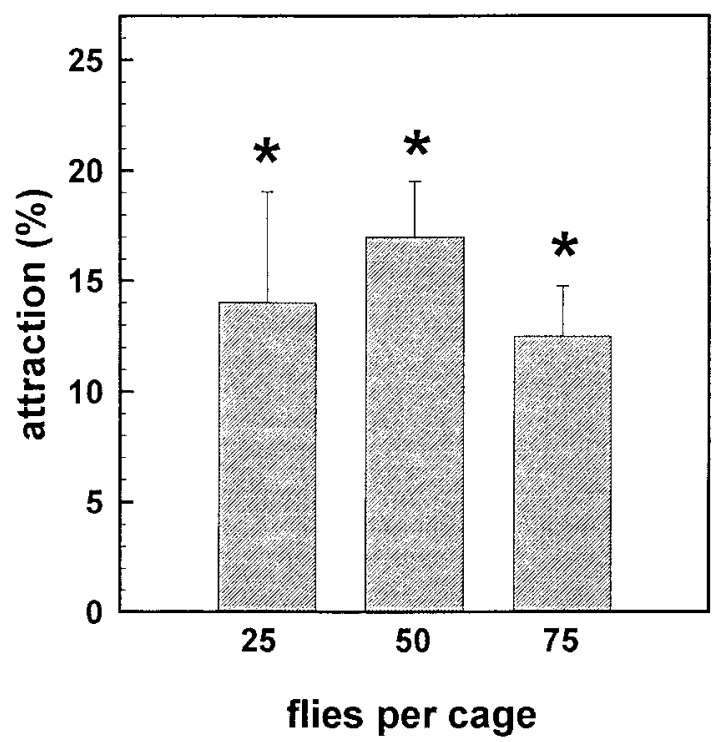

Fig. 2. Attraction of S. calcitrans females to a human hand at 3 densities of flies in an olfactometer cage. Asterisks indicate significant difference from respective control $(P \leq$ $0.003)$. Each value is the mean of 6 replicates. Vertical lines are standard error.

were used. The lowest $\mathrm{CO}_{2}$ flow rate used $\left(0.0001 \mathrm{~m} \mathrm{~s}^{-1}\right)$ failed to produce significant activation $(F=1.5, \mathrm{df}=48, P=0.14)$.

Figure 7 shows that a significant orientation toward the cage front was recorded when $0.01 \mathrm{~m} \mathrm{~s}^{-1}$ of $\mathrm{CO}_{2}$ was used $(F=10.9, \mathrm{df}=84, P<0.000001)$. The 2 lower

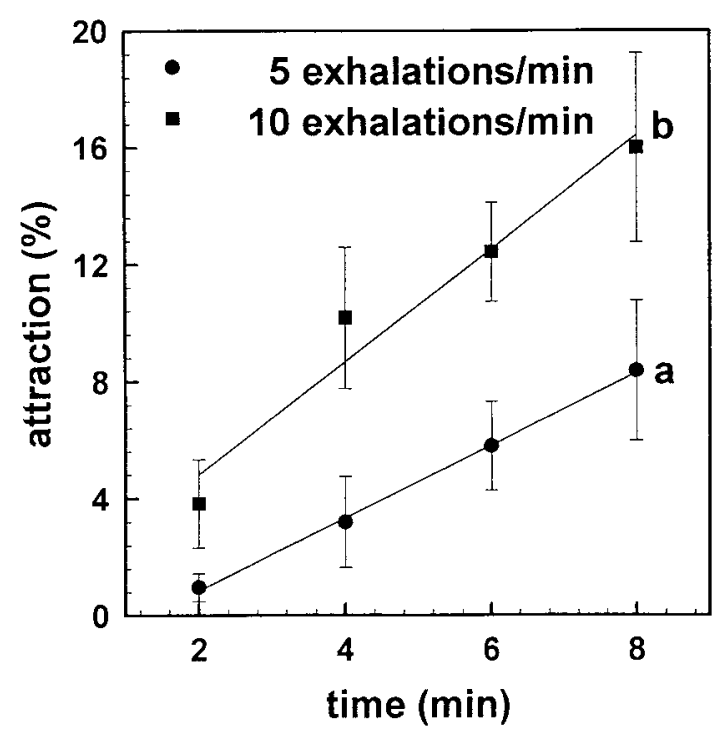

Fig. 3. Time-attraction relationship of S. calcitrans females to human breath. Different letters indicate significant differences between treatments $(P<0.05)$. Each value is the mean of 8 replicates $(n=35-40)$. Vertical lines are standard error.

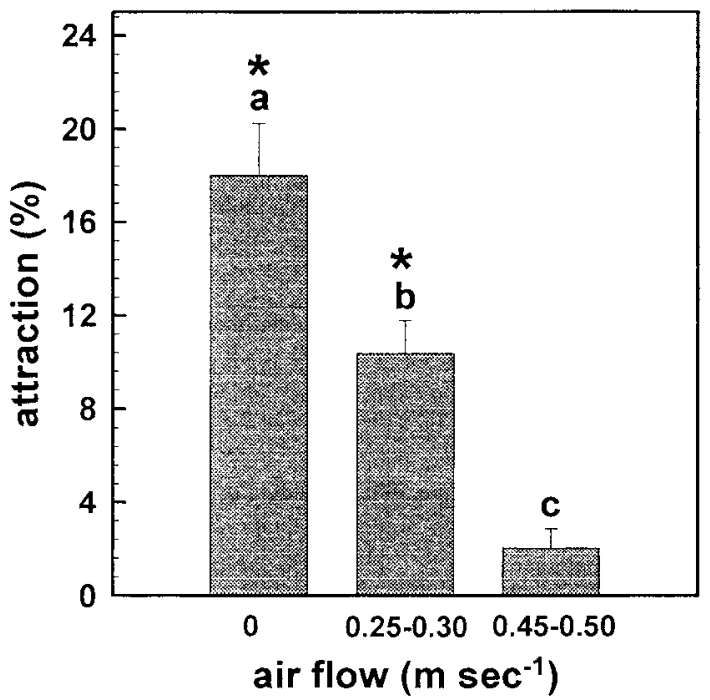

Fig. 4. Attraction of S. calcitrans females to human breath at 3 air flows. Asterisks indicate significant difference from respective control $(P \leq 0.0002)$. Different letters indicate significant differences caused by air flow $(P<0.05)$. Each value is the mean of 10 replicates $(n=38-42)$. Vertical lines are standard error.

flow rates failed to produce a significant orientation $(F=1.4, \mathrm{df}=84, P=0.20$ for $0.0001 ;$ and $F=1.6, \mathrm{df}=$ $84, P=0.10$ for $0.001 \mathrm{~m} \mathrm{~s}^{-1}$ ).

$\mathrm{CO}_{2}$ elicited probing behavior in a dose-dependent manner (Table 4). When $0.001 \mathrm{~m} \mathrm{~s}^{-1}$ of $\mathrm{CO}_{2}$ was used, a significantly higher proportion of flies probing was

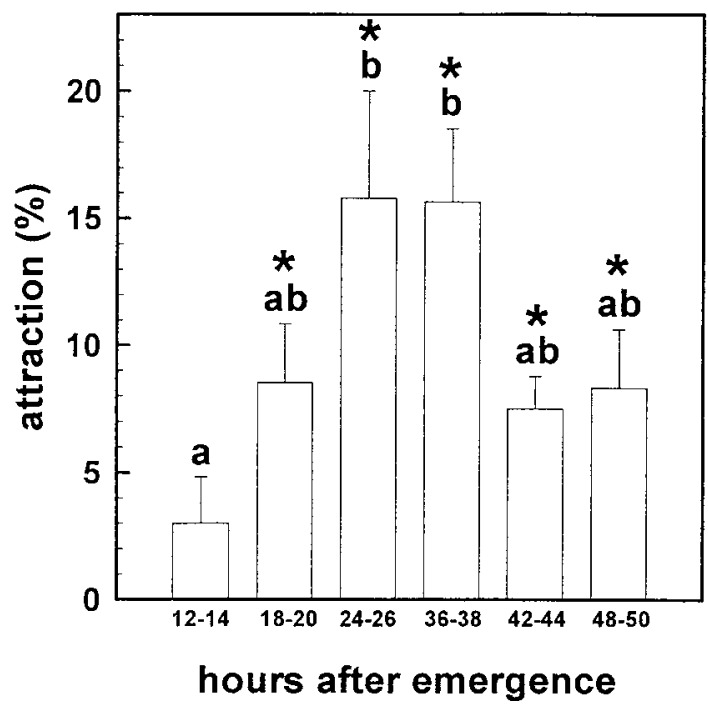

Fig. 5. Influence of age on S. calcitrans female attraction to human breath. Asterisks indicate significant difference from respective control $(P \leq 0.05)$. Different letters indicate significant differences caused by air flow $(P<0.05)$. Each value is the mean of 5 replicates $(n=25-47)$. Vertical lines are standard error. 
Table 3. Mean $\pm \mathrm{SE}$ percent attraction of $S$. calcitrans females to $\mathrm{CO}_{2}$

\begin{tabular}{lcc}
\hline \multicolumn{1}{c}{ Treatment } & $\begin{array}{c}\text { Attraction, } \\
\% \pm \mathrm{SE}\end{array}$ & $\begin{array}{c}\text { Significance of differences } \\
\text { from the control }\end{array}$ \\
\hline $\mathrm{CO}_{2}\left(0.0001 \mathrm{I} \mathrm{s}^{-1}\right)$ & $1.7 \pm 0.7$ & 0.64 \\
$\mathrm{CO}_{2}\left(0.001 \mathrm{I} \mathrm{s}^{-1}\right)$ & $1.3 \pm 0.5$ & 0.09 \\
$\mathrm{CO}_{2}\left(0.01 \mathrm{I} \mathrm{s}^{-1}\right)$ & $3.5 \pm 1.5$ & 0.10 \\
$\mathrm{CO}_{2}\left(0.038 \mathrm{I} \mathrm{s}^{-1}\right)$ & 0 & 1 \\
$\mathrm{Human}$ breath $(10$ & $12.4 \pm 1.7$ & 0.02 \\
exhalations/min $)^{a}$ & & \\
\hline
\end{tabular}

${ }^{a}$ Positive control. Each value is the mean of 6 replicates $(n=$ $35-40)$.

observed than when $0.0001 \mathrm{~m} \mathrm{~s}^{-1}$ was used $(P=$ $0.0008)$.

In preliminary tests, neither fresh blood, often tested in the past as an attractant, nor L-lactic acid in a number of forms and formulations that attract Aedes aegypti (L.) mosquitoes was seen to have any attractant effect on colony stable flies (D.A.C., unpublished data). Although these preliminary tests of L-lactic acid showed no effect on flies, we tested several related compounds. All of them failed to trap flies when applied at 10,100 , or $1,000 \mu \mathrm{g}$, although orientation was observed in most cases. The results of these experiments are summarized in Table 5. Similarly, orientation but not attraction was observed in most cases when several human odor components or related compounds were tested (Table 6).

\section{Discussion}

The current work used a triple cage olfactometer with insect traps for evaluating female S. calcitrans

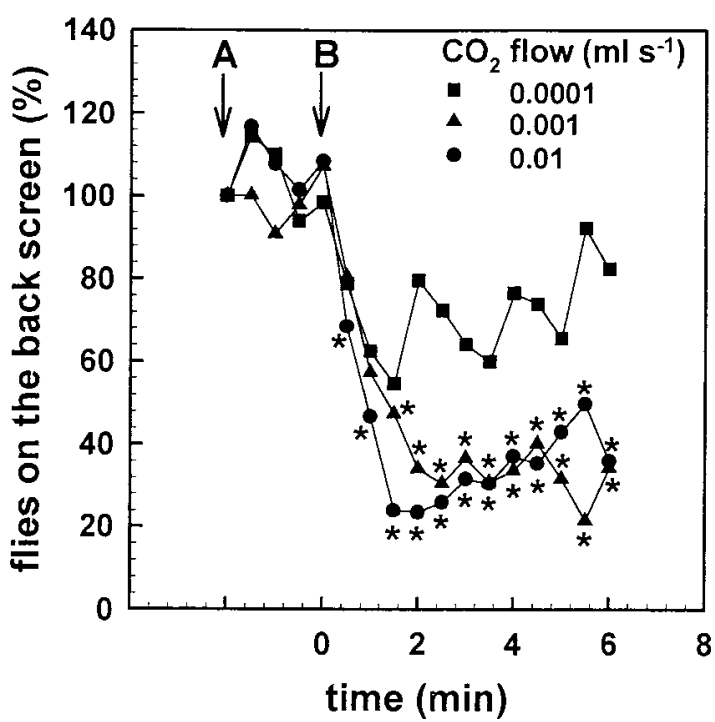

Fig. 6. Activation response of $S$. calcitrans females to $\mathrm{CO}_{2}$. (A) Opening of the trap port. (B) The beginning of the $\mathrm{CO}_{2}$ application (time $=0$ ). Asterisks indicate significant differences from the value at time $=0(P<0.005)$. Each value is the mean of 8 replicates $(n=35-40)$.

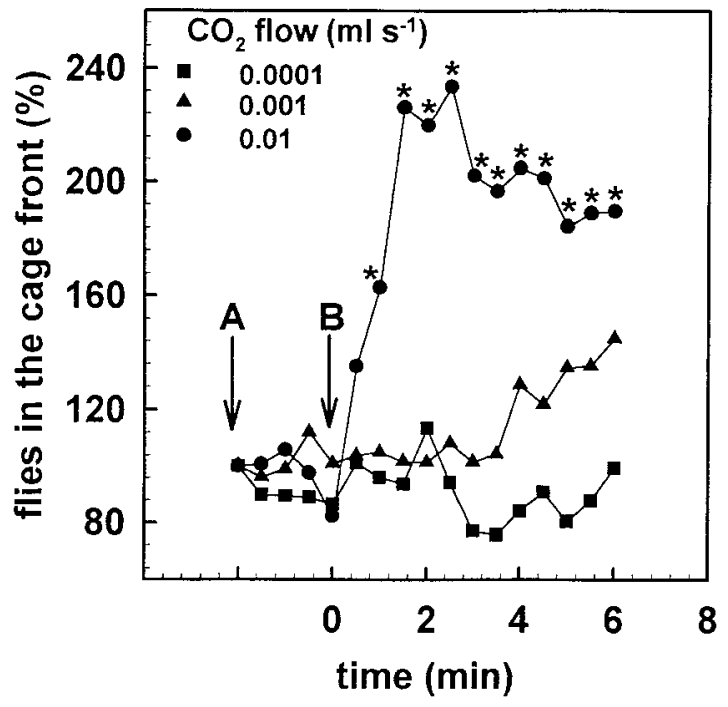

Fig. 7. Orientation response of $S$. calcitrans females to $\mathrm{CO}_{2}$. (A) Opening of the trap port. (B) The beginning of the $\mathrm{CO}_{2}$ application (time $\left.=0\right)$. Asterisks indicate significant differences from the value at time $=0(P<0.004)$. Each value is the mean of 8 replicates $(n=35-40)$.

behavioral response to attractants. This system allows a more direct and accurate quantification of behavioral response than previously used systems, as has been described above. The use of a system provided with insect traps for evaluating S. calcitrans attractants is reported here.

Our results demonstrated that neither cage position nor time of day were a significant source of variation in female S. calcitrans response. We observed no significantly different responses with air flow temperatures within a range of $\pm 2^{\circ} \mathrm{C}\left(24-28^{\circ} \mathrm{C}\right)$. Fly density between 25 and 75 flies per cage had no effect on attraction, giving a margin of flexibility for using a variable number of individuals depending on what is available from a colony.

The flight activity of a single fly (Warnes and Finlayson 1985a) or of 4 flies together (Schofield et al. 1997) has been used previously as a measure of fly activation. In the current work, we obtained consistent results placing 50 individuals into the test cages and counting the number resting on the rear screen (which varied between 14 and 21 before the treatment was presented). Increasing the size of the experimental population may allow a reduction in the number of

Table 4. Probing behavior of $S$. calcitrans females elicited by $\mathrm{CO}_{2}$

\begin{tabular}{lcccc}
\hline \hline Treatment & $\begin{array}{c}\text { No. of flies } \\
\text { tested }\end{array}$ & $\begin{array}{c}\text { No. of flies } \\
\text { probing }\end{array}$ & Chi-square \\
\hline Control & 21 & 1 & 0.05 & $<0.0001$ \\
$\mathrm{CO}_{2}\left(0.0001 \mathrm{I} \mathrm{s}^{-1}\right)$ & 21 & 6 & 0.0008 & $<0.0001$ \\
$\mathrm{CO}_{2}\left(0.001 \mathrm{I} \mathrm{s}^{-1}\right)$ & 21 & 17 & & \\
\hline
\end{tabular}


Table 5. Attraction and orientation response of $S$. calcitrans females to L-lactic acid related compounds

\begin{tabular}{|c|c|c|}
\hline Compound $^{a}$ & Orientation & Attraction \\
\hline Glycolic acid & - & - \\
\hline Oxalic acid & + & - \\
\hline DL-Glyceric acid & - & - \\
\hline DL-Malic acid & - & - \\
\hline Succinic acid & + & - \\
\hline DL-Mandelic acid & + & - \\
\hline Adipic acid & + & - \\
\hline Human hand ${ }^{c}$ & + & + \\
\hline Human breath & + & + \\
\hline
\end{tabular}

\footnotetext{
${ }^{a}$ Applied as residues of an acetonic solution on a vial cap; three amounts of each compound were tested: 10, 100, and 1,000 $\mu \mathrm{g}$.

${ }^{b}$ No attraction higher than $3.3 \%$ was observed at any volume assayed.

${ }^{c}$ Positive controls.
}

replicates, especially considering the variation that has been reported when individual stable flies were used (Gatehouse 1970).

Host-orientated behavior of hematophagous Diptera is elicited by both visual and olfactory stimuli (Gibson and Torr 1999). In the laboratory, S. calcitrans was activated (Warnes and Finlayson 1985a) by expired human breath, and a precise upwind orientation to source of human skin odor was reported (Gatehouse and Lewis 1973). Here, an optimum response to a human hand was observed when the air flow was $0.25-0.30 \mathrm{~m} \mathrm{~s}^{-1}$ that decreased at higher and lower air flows. The response to human breath decreased when air flow increased and the highest response was observed when air flow was absent. This effect of the air flow on the response of female $S$. calcitrans to odors and the ability of the flies to respond to an intermittently applied stimulus are similar to results reported in studies on tsetse flies. An inverted U-shaped relationship was observed between the wind speed and the catch of tsetse flies at odor baits (Brady et al. 1995). It was attributed to air turbulence and increased dilution of the attractant odor, which reduces the "active space" of the odor plume. Turbulent diffusion causes odor packets to mix with clean air, thereby diluting the packets of odor and reducing the strength of the host signal. Because turbulence increases when wind speed increases, the strength of the signal in an odor plume decreases when wind speed increases (Griffiths and Brady 1995). Flying insects probably detect and respond to changes in the frequency of odor packets and the relative concentration of the odor within these packets more readily than to changes in the mean concentration of odor in the plume (Gibson and Torr 1999). In laboratory studies (Gillies 1980), mosquitoes responded to $\mathrm{CO}_{2}$ when presented as a pulsed stimulus. These results probably reflect what happens in the field, where because of air turbulence the stimulus must be received intermittently.

Female S. calcitrans 24-26 and 36-38 h old were more attracted by human breath than other ages, and no differences in response with respect to controls were found in 12-14 h flies. A similar response profile was observed in flies feeding on blood; Lee and Davies (1979) reported that the majority of stable flies refused a blood meal when $<12$ h old, but most readily took blood from either a warm blood pad or a human arm when $\approx 1 \mathrm{~d}$ old. However, the flies took water or sucrose solution when $3 \mathrm{~h}$ old. A delay in the maturation of chemoreceptors for blood has been suggested as the reason for this differential response.

$\mathrm{CO}_{2}$ is an important cue in the host-location of blood-sucking Diptera (Gatehouse and Lewis 1973, Gillies 1980, Vale 1980). S. calcitrans responded to an increase in $\mathrm{CO}_{2}$ concentration by an increase in flight activity (Warnes and Finlayson 1985a, Schofield et al. 1997) and upwind anemotaxis (Warnes and Finlayson 1985b, Schofield and Brady 1997). After studying the landing of S. calcitrans on artificial targets located close to several host odor sources, Gatehouse and Lewis (1973) suggested that $\mathrm{CO}_{2}$ induced merely orientation but not precisely attraction. Our results support this hypothesis, because $\mathrm{CO}_{2}$ concentrations that elicited both female S. calcitrans activation and orientation failed to trap the flies. The highest $\mathrm{CO}_{2}$ concentration tested was 0.038 liter $\mathrm{s}^{-1}$, which is roughly equivalent to the amount produced by an ox (Gibson and Torr 1999).

Table 6. Attraction and orientation response of $S$. calcitrans females to synthetic compounds reported to be present or related to those present in human skin

\begin{tabular}{|c|c|c|c|c|}
\hline Compound $^{a}$ & Reported in & Reference & Orientation & Attraction $^{b}$ \\
\hline Pentane & $\mathrm{HE}$ & Ellin et al. 1974 & + & - \\
\hline Hexane & $\mathrm{HB}$ & Krotoszynski et al. 1977 & + & - \\
\hline 1-octen-3-ol & HS & Cork and Park 1996 & - & - \\
\hline 4-Hexen-1-ol ${ }^{c}$ & NR & & + & - \\
\hline 1-Octyn-3-ol ${ }^{c}$ & NR & & + & - \\
\hline Acetone & $\mathrm{HB}$ & Krotoszynski et al. 1977 & + & - \\
\hline 4-methyl-3-penten-2-one & $\mathrm{HE}$ & Ellin et al. 1974 & + & - \\
\hline Human hand ${ }^{d}$ & & & + & + \\
\hline Human breath ${ }^{d}$ & & & + & + \\
\hline
\end{tabular}

HB, human breath; HE, human effluents (skin + breath); NR, not reported as human odor.

${ }^{a}$ Applied pure in 2 types of containers: glass tubes ( $225 \mu \mathrm{l}, 3 \mathrm{~mm}$ diameter) and black vial caps (400 $\mu \mathrm{l}, 9 \mathrm{~mm}$ diameter). Three volumes of each compound were tested: 1 insert, 3 glass tubes and a black cap.

${ }^{b}$ No attraction higher than $3.3 \%$ was observed at any amount assayed

${ }^{c}$ Related to 1-octen-3-ol.

${ }^{d}$ Positive controls. 
In S. calcitrans, no probing behavior was observed by other authors when $\mathrm{CO}_{2}$ was used as stimulus (Hopkins 1964, Gatehouse 1970). However, we observed probing activity elicited by $\mathrm{CO}_{2}$ in a concentration-dependent way. A possible reason for these contradictory results is that all of them were realized under different experimental conditions. Hopkins' experiments were done at a lower relative humidity than ours $(60 \%)$, whereas Gatehouse's experiments were perfomed at a higher temperature $\left(35^{\circ} \mathrm{C}\right)$. Gatehouse (1970) reported that variations in temperature and relative humidity have an important influence on probing response of $S$. calcitrans to odors different than $\mathrm{CO}_{2}$. Futhermore, we worked with absolutely starved flies, whereas the other 2 authors worked with blood fed, visibly engorged flies.

L-lactic acid is present in human effluvia (Ellin et al. 1974), and it acts as an attractant for yellowfever mosquitoes (Acree et al. 1968), as do several related compounds (Carlson et al. 1973). We tested several L-lactic acid related compounds in female S. calcitrans. All of them failed to trap flies although orientation was observed in some cases. We also tested a number of synthetic human odor or related compounds, obtaining weak similar results: orientation in most cases but no trapping.

Previous work has demonstrated that acetone elicits both activation (Schofield et al. 1997) and upwind orientation in S. calcitrans (Warnes and Finlayson 1985b). Schofield and Brady (1997) reported very low flight activity in response to 1-octen-3-ol, which had an arrestant effect at high concentrations. Our results with these 2 compounds are consistent with the previous results, in that acetone but not 1-octen-3-ol elicited orientation and both of them failed in trapping $S$. calcitrans. The current studies showed that acetone and most of the remaining compounds are similar to $\mathrm{CO}_{2}$, eliciting weak orientation to its source. It should be noted that a recent field study showed that several combinations of Alsynite sticky panels with $\mathrm{CO}_{2}$, 1-octen-3-ol, acetone, and a phenolic mixture of phenols were attractive (Cilek 1999).

More studies with these and other human odors should be done to identify those that play an important role in host-location by S. calcitrans. In particular, combinations should be tested to look for possible synergistic interactions.

The advantages of using a triple cage olfactometer for evaluating insect attractants were discussed by Posey et al. (1998). Briefly, this cage allows several replicates of a test to be done, and 9 different attractants can be tested in a single day; in addition, its space requirements are lower than for other olfactometer designs. The incorporation of insect traps is also an improvement compared with systems previously used to study stable flies because it permits differentiation between a mere orientation and a more precise attraction to a stimulus source.

Stable flies readily entered the screen cone when stimulated by an attractive odor, often by walking after landing. Our data indicate that the triple cage olfactometer can be used to evaluate the different steps involved in host location by S. calcitrans (activation, orientation, attraction, and probing). It can also be used for separating odors that elicit mere orientation, as $\mathrm{CO}_{2}$, from a mixture of chemical odors that elicit a more precise attraction to its source.

\section{Acknowledgments}

We thank Donald Barnard for physical arrangements and interest in our work; Jerry Hogsette, Daniel Kline, and Alberto Broce for critical reading of the manuscript; and José Monserrat for suggestions about statistical analysis. R.A.A. received a World Health Organization Visiting Scientist Grant, and a fellowship from Consejo Nacional de Investigaciones Científicas y Técnicas de Argentina.

\section{References Cited}

Acree, F., Jr., R. B. Turner, H. K. Gouck, M. Beroza, and N. Smith. 1968. L-Lactic acid: A mosquito attractant isolated from humans. Science (Wash. D.C.) 161: 1346-1347.

Brady, J., N. Griffiths, and Q. Paynter. 1995. Wind speed effects on odour source location by tsetse flies (Glossina). Physiol. Entomol. 20: 293-302.

Campbell, J. B., R. G. White, J. E. Wright, R. Crookshank, and D. C. Clanton. 1977. Effects of stable flies on weight gains and feed efficiency of calves on growing or finishing rations. J. Econ. Entomol. 70: 592-594.

Campbell, J. B., I. L. Berry, D. J. Boxler, R. L. Davis, D. C. Clanton, and G. H. Deutscher. 1987. Effects of stable flies (Diptera: Muscidae) on weight gain and feed efficiency of feedlot cattle. J. Econ. Entomol. 80: 117-119.

Carlson, D. A., N. Smith, H. K. Gouck, and D. R. Godwin. 1973. Yellowfever mosquitoes: Compounds related to lactic acid that attract females. J. Econ. Entomol. 66: $329-331$

Cilek, J. E. 1999. Evaluation of various substances to increase adult Stomoxys calcitrans (Diptera: Muscidae) collections on Alsynite cylinder traps in North Florida. J. Med. Entomol. 36: 605-609.

Cork, A., and K. C. Park. 1996. Identification of electrophysiologically-active compounds for the malaria mosquito, Anopheles gambiae, in human sweat extracts. Med. Vet. Entomol. 10: 269-276.

Ellin, R. I., R. L. Farrand, F. W. Oberst, C. L. Crouse, N. B. Billups, W. S. Koon, N. P. Musselman, and F. R. Sidell. 1974. An apparatus for the detection and quantitation of volatile human effluents. J. Chromatogr. 100: 137-152.

Foil, L. D., and J. A. Hogsette. 1994. Biology and control of tabanids, stable flies and horn flies. Rev. Sci. Tech. Off. Int. Epizoot. 13: 1125-1158.

Gatehouse, A. G. 1970. The probing response of Stomoxys calcitrans to certain physical and olfactory stimuli. J. Insect Physiol. 16: 61-74.

Gatehouse, A. G., and C. T. Lewis. 1973. Host location behaviour of Stomoxys calcitrans. Entomol. Expt. Appl. 16: 275-290.

Gibson, G., and S. J. Torr. 1999. Visual and olfactory responses of haematophagous Diptera to host stimuli. Med. Vet. Entomol. 13: 2-23.

Gillies, M. T. 1980. The role of carbon dioxide in host-finding by mosquitoes (Diptera: Culicidae): a review. Bull. Entomol. Res. 70: 525-532.

Griffiths, N., and J. Brady. 1995. Wind structure in relation to odour plumes in tsetse fly habitats. Physiol. Entomol. 20: $286-292$. 
Hogsette, J. A. 1992. New diets for production of house flies and stable flies (Diptera: Muscidae) in the laboratory. J. Econ. Entomol. 85: 2291-2294.

Hopkins, B. A. 1964. The probing response of Stomoxys calcitrans (L.) (the stable fly) to vapours. Anim. Behav. 12: 513-524.

Krotoszynski, B., G. Gabriel, and H. O’Neill. 1977. Characterization of human expired air: a promising investigative and diagnostic technique. J. Chromatogr. Sci. 15: 239-244.

Lee, R.M.K.W., and D. M. Davies. 1979. Feeding in the stable fly, Stomoxys calcitrans (Diptera: Muscidae) I. Destination of blood, sucrose solution and water in the alimentary canal, the effects of age on feeding, and blood digestion. J. Med. Entomol. 15: 541-554.

Newson, H. D. 1977. Arthropod problems in recreation areas. Annu. Rev. Entomol. 22: 333-353.

Posey, K., D. R. Barnard, and C. E. Schreck. 1998. Triple cage olfactometer for evaluating mosquito (Diptera: $\mathrm{Cu}-$ licidae) attraction responses. J. Med. Entomol. 35: 330 334 .

Schofield, S., and J. Brady. 1997. Effects of carbon dioxide, acetone and 1-octen-3-ol on the flight responses of the stable fly, Stomoxys calcitrans, in a wind tunnel. Physiol. Entomol. 22: 380-386.
Schofield, S., C. Witty, and J. Brady. 1997. Effects of carbon dioxide, acetone and 1-octen-3-ol on the activity of the stable fly, Stomoxys calcitrans. Physiol. Entomol. 22: 256260.

Sokal, R. R., and F. J. Rohlf. 1969. Biometry. Freeman, San Francisco, CA.

Vale, G. A. 1980. Field studies of the responses of tsetse flies (Glossinidae) and other Diptera to carbon dioxide, acetone and other chemicals. Bull. Entomol. Res 70: 563-570.

Warnes, M. L., and L. H. Finlayson. 1985a. Responses of the stable fly, Stomoxys calcitrans (L.) (Diptera: Muscidae), to carbon dioxide and host odours. I. Activation. Bull. Entomol. Res. 75: 519-527.

Warnes, M. L., and L. H. Finlayson. 1985b. Responses of the stable fly, Stomoxys calcitrans (L.) (Diptera: Muscidae), to carbon dioxide and host odours. I. Orientation. Bull. Entomol. Res. 75: 717-727.

Wieman, G. A., J. B. Campbell, J. A. Deshazer, and I. L. Berry. 1992. Effects of stable flies (Diptera: Muscidae) and heat stress on weight gain and feed efficiency of feeder cattle. J. Econ. Entomol. 66: 1279-1280.

Received for publication 28 June 1999; accepted 14 October 1999. 